\title{
Sigue sus huellas y búscala: "La sapiencia" según las memorias de Jesús, el hijo de sirá
}

\begin{abstract}
Resumen: Con un tono dialógico, académico y pastoral, el presente artículo es un marco general de interpretación que introduce a los lectores al estudio histórico-crítico del libro de Ben Sirá o Eclesiástico. También hace algunas observaciones hermenéuticas y provee una breve crítica, a fin de resaltar la relevancia del contenido de este libro a la luz de algunos desafíos contemporáneos.

Palabras clave: Escritos, Eclesiástico, Ben Sirá, Sabiduría, Literatura sapiencial, Diáspora, Judaísmo

Abstract : With a dialogical, academic and pastoral tone, this article is a general framework of interpretation that introduces readers to the historical-critical study of the book of Ben Sira or Ecclesiasticus. It also makes some hermeneutical observations and provides a brief critique, in order to highlight the relevance of the content of this book in light of some contemporary challenges.

Keywords: Writings, Eclessiasticus, Ben Sirach, Wisdom, Wisdom literature, Diaspora, Judaism.
\end{abstract}

Tener "sabiduría" no es discurrir magistralmente sobre ella. Es más bien una actitud o hasta un don, una manera de ver el mundo con significado, coherencia y propósito. Diríamos que es como desenvolverse en la vida de mano con los cinco sentidos, más un sexto que es como una aureola, llámesele "intuición" o "discernimiento". Más que ciencia, inteligencia o entendimiento, la sabiduría es a la vida humana lo que al cuerpo es el alma, la musa del existir en su sentido más banal pero insondable a la vez. En fin, un sinnúmero de sentires, saberes y quehaceres por la senda de insaciables memorias de esos pueblos e historias, en la entrega a la divinidad por medio de la entrega a la vida y favor de la vida en todos sus despliegues de vida...

Este desborde entusiasmo de sentimientos no emerge ex nihilo; tienen su génesis en la rica tradición de los pueblos del Antiguo Cer- 
cano Oriente, especialmente de la comunidad hebrea. En el AT, pensar en la sabiduría era comunicar por escrito una manera particular de referirse a la vida sobre la base de experiencias; es decir era un "tipo de literatura" o "cuerpo literario" ${ }^{1}$. Pero, por encima de eso, fue un modo de ver y acercarse a la vida por medio de algunos recuerdos de esa cotidianidad de aciertos y desaciertos transformados en prácticos consejos, jamás un cúmulo de abstracciones o complicaciones filosóficas. Casi herméticas a los actos salvíficos de Dios en la historia y la denuncia profética, estos consejos prácticos, de tono sencillo, se centraban en la cordura, la moderación y el tacto, todo con el fin de lograr una vida balanceada, feliz y plena. Contra los vicios morales y siempre cultivando las virtudes, la sabiduría consistía en vivir una vida conforme a los designios divinos ${ }^{2}$.

Muchos han sido quienes en la historia del pueblo hebreo se han dedicado a tratar de definir esta "sapiencia" de proporciones milenarias. Pero un maestro de antaño, en particular, del gentilicio hebreo por providencia, desde su juventud, después de haber viajado por muchas partes del mundo, y teniendo a Dios como su etiología y utopía expresada en la Ley de Moisés, tuvo a bien buscar a la sabiduría casi toda su vida, para luego compartir con las generaciones futuras las lecciones acumuladas con el correr de los años.

Su nombre: Jesús, hijo de Sirá, hijo de Eleazar. Su obra: una antología de valores, principios y reglas en cuanto a cómo vivir una vida con significado y destino, anclada en Dios y su Ley, y expresada en las buenas relaciones con el ser personal y los semejantes, la cual terminó albergándose en un libro cuyo título honra a su autor: Ben Sirá. Su lugar y fecha: Jerusalén, y luego Alejandría, Egipto, hacia el segundo siglo a.C. Su agente: un nieto dispuesto a preservar las aleccionadoras memorias de su abuelo en beneficio de personas que como él vivían "regadas" por el mundo y luchaban por rehacer sus vidas fuera de la madre tierra. El fruto: un sitial privilegiado dentro de las Sagradas Escrituras de los judíos y de las comunidades cristianas, siglos más tarde.

No es regla el que un libro bíblico nos dé detalles sobre muchos de los factores que lo originaron. Ben Sirá o Eclesiástico es una grata

Así, por ejemplo, se habla de "la tradición sapiencial" que incluye los libros de Job, Salmos, Proverbios, Eclesiastés, Cantar de los Cantares y Sabiduría, y pasajes y temas sapienciales en otros géneros literarios del AT, que se ajustan a esta manera de escribir y proceder ante la vida. Crenshaw, James L. (1981), Old Testament Wisdom: An Introduction, John Knox Press, Atlanta, pp. 11-25; Boadt, Lawrence (1984), Reading the Old Testament: An Introduction Paulist Press, NY, pp. 472-479. 
excepción ${ }^{3}$. Para ayudar a realizar una lectura situada en el espacio, el tiempo y el entorno social de este libro, procede, entonces, resaltar algunos aspectos contextuales del mismo, precisamente como un intento por caminar tras las improntas de esa inteligencia especial, siempre enraizada en el ayer de los pueblos.

\section{La elocuencia de un mote literario}

Siendo el último y más extenso de todos los libros sapienciales del AT, y el único que explícitamente identifica a su autor y traductor ${ }^{4}$, además de otros atributos sin parangón, a esta gran obra, ubicada en el canon griego del AT entre los libros de Sabiduría e Isaías, se le identifica por medio de varios "títulos". Sin embargo, una lectura ávida de curiosidad muestra que éstos no son más que simples y arbitrarios epígrafes con tintes meramente decorativos. La acción de "nombrar" es un acto situado y de poder que refleja interpretación e intencionalidad. Dicho de otro modo, es un "acto hermenéutico" de mucha utilidad pero a la vez condicionante ${ }^{5}$.

Resaltando lo que parece ser el tema principal del libro y la identidad de quien lo puso por escrito, la gran mayoría de los manuscritos griegos de la traducción griega del AT o LXX, y algunas copias traducidas al latín más tarde (quienes aparte de retener la identidad del autor, reemplazan la palabra "sabiduría" por "libro"), bautizan a este libro

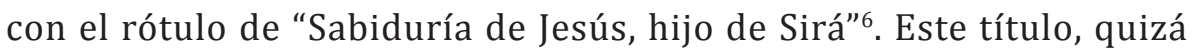
tomado de la acotación luego de 51,30, es una traducción del hebreo Ben Sirá, del cual se deriva la abreviación convencional Sirácida para

3 Para el presente trabajo he consultado las siguientes fuentes: Olvera Pérez, Cirilo (2007), Eclesiástico o Sabiduría de Ben Sirác. En: “Comentario bíblico latinoamericano: Antiguo Testamento II Libros proféticos y sapienciales”. Verbo Divino, Estella, vol II, pp. 915-922; Metzger, Bruce M. (1980) An Introduction to the Apocrypha, Oxford University Press, NY, pp. 77-78; Harrington, Daniel J. (1999), Invitation to the Apocrypha, Eerdmans, Grand Rapids, pp. 78-91; Rost, Leonhard (1976), Judaism Outside the Hebrew Canon, Abingdon Press, Nashville, pp. 64-69; Crenshaw, J. op. cit. pp. 149-173; Tunseth, Scott (2009), Ecclesiasticus, or the Wisdom of Jesus Son of Sirach. En 'The People' Bible, Augsburg/Fortress, Minneapolis, pp. 1191-1992; Wright, Benjamín G. (2006), Ecclesiasticus, or the Wisdom of Jesus Son of Sirach. En: The Harper Collins Study Bible, Harper One, NY, pp. 1378-1380.

4 Es decir, Job, Salmos, Proverbios, Eclesiastés, Cantar de los Cantares y Sabiduría.

5 Darle un nombre a un libro por medio de algunas frases selectas arroja información sobre la interpretación de quién escoge el nombre y su entorno, qué áreas del libro adquieren visibilidad y cuáles dimensiones de su contenido son empujadas hacia las márgenes o, peor aún, al anonimato de los lectores.

6 Curiosamente, los manuscritos existentes -quizá por economía de palabras- excluyeron la frase “hijo de Eleazar", que también está en el libro para identificar a su autor $(50,27)$. 
identificar al autor ${ }^{7}$. El título hebreo original no ha sido preservado en ningún manuscrito, pues ha sobrevivido en traducciones griegas y hebreas posteriores. Suponemos que por medio de un proceso invertido el título original debió haber sido algo como Yeshua ben El-azar ben Sira.

Dándole crédito a su autor, y resaltando la relación del libro con la Ley Mosaica y la utilidad pedagógica de éste, en la tradición judaica de cultura helenista se le conocía como "el libro ("instrucción o Torá") de Ben Sira" . Cabe preguntarse si el haber estado fuera de la tierra madre y la nostalgia por la Ley Mosaica, fueron factores incidentes en la selección de este epíteto, además de la naturaleza práctica, imperativa y pedagógica de la obra del Sirácida.

Siglos más tarde, en la mayoría de los manuscritos latinos, en su traducción de la LXX (es decir la Vulgata) y comenzando con el padre Cipriano ${ }^{9}$, la tradición cristiana identificó a esta obra como "Eclesiástico", especialmente en la Iglesia católico-romana ${ }^{10}$. Este título significa literalmente "(libro) perteneciente o relativo a la asamblea", es decir la iglesia, y fue adoptado porque se lo utilizaba frecuentemente en el catecumenado y formación de otros cristianos. El uso, más que el contenido mismo o de darle crédito al autor, pasó a ser el criterio principal de nombramiento. Con el paso del tiempo se le llamó "el libro de Eclesiástico". Otros, por razones más prácticas o economía de palabras, le llamaron "Ben Sirá" o "Sirá"11.

\section{Los protagonistas de una gran obra}

Después de conocer al libro por sus títulos, sigue la identificación y descripción de todos los actantes que tienen algo que ver con la producción de Eclesiástico.

El nombre completo del autor, dicho por él mismo y corroborado por su nieto, es “Jesús, hijo de Sirá, hijo de Eleazar, de Jerusalén” (50,27; 51,30. Ver también el prólogo adicionado). Como el mismo libro deja

Es decir, "Sirácides," Septuaginta. Cf. Rahlfs, Alfred (1979), Deutsche Bibelgesellschaft, Stuttgart, p. 377.

8 Ver, por ejemplo, "Liber Iesu Filii Sirach", Biblia Sacra Iuxta Vulgatam Versionem, Deutsche Bibelgesellschaft, Stuttgart, 1983, vol. ii, p. 1029.

$9 \quad$ Ver Testimonia ii. 1; iii. 1, 35, 51, 95, et al. Olvera Pérez, p. 915.

10 Dentro de la tradición sapiencial veterotestamentaria hay otro libro cuya traducción al griego y luego al latín tiene un significado parecido. Es "Eclesiastés", que literalmente significa "miembro de la asamblea" o "asambleísta".

11 Dada la riqueza semántica y la validez funcional de todos los títulos dados al mismo libro, es saludable utilizarlos a todos por razones de sencillez y practicidad, es decir como designaciones sinónimas para fines netamente comunicacionales. 
ver, su autor era un judío de Jerusalén, culto, de buena posición socio-económica y experto en la ley mosaica y otras tradiciones hebreas. Aunque no parece haber sido sacerdote, además de la Torá, conocía a fondo los Profetas y Escritos y las prácticas religiosas del pueblo de la Alianza Mosaica, es decir toda la Escritura Hebrea conocida entonces. En cuanto a su pensamiento religioso, el autor parece servir de trasfondo a la futura teología de los saduceos, precisamente por sus afinidades ${ }^{12}$. Es muy probable que haya dirigido una escuela en Jerusalén, destinada a formar a los jóvenes en la adquisición de la sapiencia divina $(51,23)$. Él se describe a sí mismo como "estudiante de la ley del Altísimo" (39,1-11) y "maestro" (51,23).

Desde muy joven, como él mismo rememora, este hombre sediento de "inteligencia", "juicio" y "ciencia", se dedicó al estudio y aplicación de las Escrituras y a la búsqueda de "la Sabiduría", sobre todo por medio de "la oración" $(51,13)$. Pero también, como buen observador, aprovechó sus frecuentes viajes por el mundo para completar su educación, muchas veces teniendo que enfrentar peligros de muerte $(34,11)^{13}$. No sería ilógico pensar que este Jesús haya sido miembro de una "escuela de sabios" o que incluso haya sido parte de algunas misiones diplomáticas ante reyes $(39,4)$. Pero, después de una larga y aleccionadora jornada, en el ocaso de su vida, dio por finalizado el fruto de sus reflexiones y de su multifacética experiencia de fe y vida para encaminar otras generaciones: "Yo, el último en llegar, me mantuve alerta como quien recoge detrás de los viñadores. Por la bendición del Señor he llegado a tiempo y como un viñador he llenado el lagar" (33,16-17). Y así, "colmado como la luna llena", extendió una invitación a sus discípulos diciendo: "Escúchenme hijos santos y crezcan como rosal que brota junto a la corriente de agua" $(39,12-13)$. Es como si Jesús, versión griega del nombre hebreo Josué, y cuyo significado es "Dios salva" (Cf. Mt 1,21), en su esfuerzo por instruir a los buscadores de la sapiencia, hubiese tratado de "salvar" al pueblo hebreo de la ignorancia y, en ese sentido, hizo honor a su nombre ${ }^{14}$.

\footnotetext{
12 Por ejemplo, no se enfoca en la vida venidera o en la resurrección, tiene una alta concepción de la creación divina (43,1-33), cree en la justicia divina en torno al comportamiento humano en esta vida $(11,14)$, tiene en alta estima al sacerdocio y la religión ritual centrada en el Templo (7,29-31; 11,26-28), excluye a Esdras de la galería de héroes de Israel (quien era venerado por los fariseos), y otros aspectos más. Metzger, p. 87.

13 Es posible que el capítulo 51 (y quizá otras referencias en el libro sobre la misma temática) refleje algo de ese tipo de experiencia.

14 Josué no fue el único en honrar el significado de su nombre (46,1; Cf. 2-10).
} 
En relación a la producción de Ben Sirá, no debemos excluir a quien escribió el prólogo del libro y lo tradujo al griego, persona que manteniendo un bajo y humilde perfil no da su nombre y se identifica a sí mismo como "nieto" de Jesús, además de certificar que su abuelo fue el autor $(50,27)$. No estamos en la capacidad de determinar su contribución y su papel como traductor, pero debemos recordar que en la historia de la transmisión de las tradiciones judeo-cristianas, tanto orales como escritas, no hubo tal cosa como receptores pasivos de las ideas de otros; los editores o redactores fueron también autores. Así que no tenemos por qué extrañarnos de que "el traductor" haya insertado, corregido o embellecido con algunos comentarios el trabajo original. Si bien estamos agradecidos por el trabajo del abuelo, también estamos agradecidos por el trabajo de su anónimo nieto.

\section{De los hebreos para el mundo en la dispersión}

A la hora de pensar en el lugar y la fecha que dieron a luz este magistral libro, se hace necesaria hacer una distinción entre "el documento original" y "la traducción del mismo" y, por lo mismo, tener en consideración, además de nosotros como lectores, por lo menos a dos destinatarios y dos fechas de composición originaria. En orden cronológico, primeramente, hay que pensar en los judíos palestinenses, y luego en los judíos helénicos.

Se estima que el autor del libro original, Jesús, hijo de Sirá, hijo de Eleazar, escrito en hebreo, fue terminado en Jerusalén alrededor del 180 a.C., siendo su autor de edad muy avanzada. Éste llevó a feliz término su magna opus antes de emigrar a Egipto, teniendo en mente a la comunidad hebrea residente de Palestina y otros posibles lectores. Esto concluye que, por un lado, Eclesiástico haya sido escrito antes de la revuelta de los Macabeos contra los Seléucidas, la cual explotó en reacción a las acciones de Antíoco Epifanes IV, en el 168-164 a.C., pues no hay referencia a ese evento o a las guerras subsiguientes. Por otro lado, Ben Sirá menciona al sumo sacerdote Simón $(50,1)$ en términos muy positivos, como si le conociera y fuera su contemporáneo. Se cree que este prelado fue Simón II, "el justo", quien ministró entre el 219 y 196 d.C. Esto nos hace suponer que Ben Sirá tuvo que haberse escrito en algún momento durante ese período y, obviamente, antes de su traducción al griego.

La traducción de este libro del hebreo al griego sucedió muchas décadas más tarde. En el prólogo, el nieto del Sirácida afirma haber 
arribado a Egipto "en el año treinta y ocho del rey Evergetes" (lit. "El Benefactor")", y luego de un tiempo de haber puesto mucho empeño, logró traducir la obra de su abuelo al griego, a fin de educar a quienes "en el extranjero" querían vivir conforme a la Ley Mosaica. Este rey fue probablemente Ptolomeo VIII, quien reinó entre el 145 y el 116 a.C., lo cual nos permite situar la llegada del nieto del Sirá cerca del 132 a.C., y la finalización de la traducción cerca del 117 a.C. en Alejandría, luego de la muerte de Ptolomeo.

\section{El por qué y el para qué de la sapiencia}

Si bien cada unidad que conforma al libro de Jesús tuvo sus razones y propósitos históricos particulares, la obra de Jesús como un todo acabado es un llamado de atención frente a la perniciosa influencia de la cultura griega, que no cesaba de expandirse en el Cercano Medio Oriente desde las conquistas de Alejandro Magno (356-323 a.C.) y de la que Israel fue víctima. El pueblo hebreo, dentro de Palestina, o peor aún en el mismo destierro o diáspora, se debatía entre la retención de su acervo y la asimilación de los valores impuestos de la nueva cultura. El Sirácida comprendió que ese nuevo estilo de vida no tardaría en entrar en conflicto con la fe de Israel o, lo que es peor, que diluiría su naturaleza para convertirlo en una reliquia. Pero él no fue el único. Sabiamente su nieto fue capaz de captar el valor de las enseñanzas de su abuelo para un grupo mucho más amplio que moraba fuera de Israel y por tal motivo las tradujo al griego, a fin de instruir a quienes dentro de la dispersión gentil estaban dispuestos a permitir que la ley mosaica, reinterpretada por Sirá, modificara sus estilos de vida.

Para evitar que los hebreos llegaran a esta situación, como bien lo discernió su nieto, y con ánimo de preservar sus raíces de fe y valores culturales, el sabio Jesús puso todo su empeño en preservar parte del patrimonio de fe y vida del judaísmo en esa época de dolorosa transición para compartirlo con sus hermanos y hermanas. A diferencia de muchos antiguos "maestros de sabiduría", por su misma condición de vida dentro de una realidad histórica de colonización, al Sirácida le preocupaba sobre todo la formación espiritual y moral del conglomerado de "la judería". Por eso se dedicó a reflexionar y compartir la sabiduría hebrea por él vivida. Según él, ésta fue dada especialmente a Israel como regalo divino y, en última instancia, se encarnó en la Ley de Moisés. De allí la imperiosa necesidad de estudiar y meditar, de noche 
y de día, "el libro de la alianza del Dios altísimo" (24,23), a objeto de vivir conforme con lo que Dios quiere.

Para Jesús, la meta final era "volver" a la sabiduría y colocarla en el corazón, pero más que eso era "ponerla en práctica" toda la vida $(3,29$; 6,18-19.33-37; 24,19-22; 50,28-29). Es decir, recordarla, meditarla, atesorarla y, mejor aún, vivirla: “FFeliz el que vuelve continuamente sobre estas palabras! El que las ponga en su corazón, será sabio” $(50,28)$. Quizá en el ocaso de su vida y con perspicacia introspectiva, Jesús fue ese canal que brotó de un río que, al querer regar su huerta y empapar sus canteros del agua de la sabiduría, pasó a ser un río y terminó convirtiéndose en un mar, a fin de irrigar a generaciones futuras que, como él, estén dispuestos a buscar la sabiduría (24,30-34).

\section{Prácticas instrucciones para "los sabios en formación"}

A esta realidad de "ignorancia", que luego se extiende a una realidad de "dispersión", responden las memorias éticas del abuelo Sirá. Dejando a un lado las disquisiciones doctrinales, en esta gesta de hacer de la experiencia algo aplicable y que contribuya a la formación integral de quienes aspiren a ser sabios $(38,24-39,11)$, Eclesiástico se enfoca en decir y mostrar en qué consiste vivir "la verdadera sapiencia". Aparte de explicar la naturaleza de las relaciones humanas, la idea es hablar de situaciones específicas de la vida y cómo comportarse ante ellas ${ }^{15}$. Cada una de las memorias del poeta, como bien lo capta Rufín Pardo, se volvió "repaso" y "moraleja"16.

Para este poeta-pedagogo, como para el resto de la literatura sapiencial del AT, toda sabiduría comienza, termina y se hace plena en Dios (1,1.16.20); de verdad, ella salió "de la boca del Señor" $(24,1)$. Tal es así que, en su sentido más ideal, "la sabiduría humana" y "la sabiduría divina" terminan siendo prácticamente la misma cosa. Recordemos la máxima proverbial que hizo que el Sirácida atine: "el principio de la sabiduría es el temor de Yahvé" (1,11-21; 32,14-24; 33,1-6; 40,26-27). Pero hablar de Dios es hablar de su Ley. Por eso, la verdadera ciencia o inteligencia pueden solamente hallarse en la Ley de la Alianza Mosaica; la responsabilidad humana es buscar la sabiduría en esa Ley y obedecer los dictámenes de la misma $(2,16 ; 9,15 ; 15,1 ; 17,11 ; 19,20$; $21,11 ; 32,14-16 ; 34,8.39-11 ; 51,19)$. La sabiduría es tan importante

\footnotetext{
15 Para una lista de temas más completa, ver Harrington, pp. 80-88.

16 Daylíns M. Rufín Pardo, Los cuentos del abuelo: una mirada al libro de ben Sirá. En: Debarim (2005), nota, 6.
} 
para Sirá, que magistralmente la personaliza como "la dama" o "la señora Sofía"17, atribuyéndole voluntad, pensamientos, sentimientos, actitudes y acciones nobles.

El tratamiento que Sirá le da al tema de la sapiencia brota de las páginas de Eclesiástico con dos rostros. Por una parte, hay pasajes que hablan de la sabiduría destacando su origen, identidad, valores que apadrina, cómo ponerla en práctica, quien reúne las condiciones para exhibirla, los beneficios que genera a los practicantes y otras características similares $(1,1-30 ; 4,11-19 ; 6,18-37 ; 14,20-15,10 ; 19,20$ $30 ; 24,1-34 ; 37,16-31 ; 38,24-39,11)$. A menudo se le contrasta con su opuesto que es la necedad y vicios afines $(20,7.13 .31 ; 21,11-28 ; 22$,9$15 ; 27,11-15 ; 41,15 ; 42,8)$.

Por otro lado, enmarcados dentro de estos pasajes que, directa y abiertamente nos hablan de la sabiduría, en el resto de la obra notamos ejemplos más específicos que muestran quién es sabio y quién no, aun cuando no se emplee la palabra "sabiduría" o algunos de sus sinónimos. Vemos algunos intentos por resumirla, numerando algunos valores y conductas específicas (por ejemplo: 25,1-2). Siguiendo esta lógica, con el énfasis puesto en las proezas de algunos personajes del AT, la sabiduría también es "modelada" por la lista de héroes que se menciona al final del libro. Imitar la conducta de estos paladines es "el ideal" (44,1-49,16). El sacerdote Simón, hijo de Onías, es también digno de emulación (50,1-21).

La lista de vivencias, muchas veces en términos de oposiciones binarias, sinónimos y resúmenes explicativos, es tan variada como relevante al devenir del pueblo hebreo, pero no es exhaustiva. Hay una dosis fuerte de sentido común que busca establecer un sano balance en las relaciones con Dios, como prioridad, y de relaciones con uno mismo, la familia y el prójimo. En Sirá, partiendo de una concepción del ser humano un tanto negativa, las relaciones humanas se conciben en términos de ambivalencias. Normalmente se debaten entre la justicia y la injustica, la riqueza y la pobreza, la sabiduría y la necedad o ignorancia, el egoísmo y la generosidad, la tristeza y el gozo, la vida y la muerte, la prudencia y la imprudencia, la sanidad y el dolor, y otras dualidades parecidas.

Si la extensión y repetición de algunos temas son pistas de lo que para su autor es importante, ciertos temas son prioritarios para el

17 Schüller, Eileen M. The Apocrypha. En: Newsom C.A. y Ringer, S.H. eds. (1992), “The Women's Bible Commentary", Westmister/Jonh Knox, Louisville, pp. 237-238. 
Sirácida. Tomemos, por ejemplo, la función y la condición de los ricos y de los pobres en la vida cotidiana, al igual que el uso del dinero y de la práctica de la limosna $(3,30-4,10 ; 5,1-8 ; 7,32-36 ; 10,22-31 ; 11,1$ $34 ; 13,1-14,2 ; 14,3-4 ; 18,25-26 ; 20,21 ; 26,29-27,7 ; 29,1-20 ; 31,1-11$; $33,20-33)$; la posición y función de la mujer y la relación con ellas $(9,1-9 ; 25,12-26 ; 26,1-26 ; 36,21-27 ; 42,12-14)^{18}$; el asunto de la naturaleza y la función del discurso humano $(5,9-6,1 ; 19,4-19 ; 20,1-31$; $27,8-29 ; 28,13-30)$; la amistad (6,5-17; 9,10-16; 11,29-12,18; 13,1-14,2; $22,19-26 ; 23,7-21 ; 37,1-15)$; la gloria divina mostrada en la creación $(16,24-17,10 ; 39,12-35 ; 42,15-43,33)$; el culto $(34,18-35,18 ; 50,1-21)$, y el orgullo y la humildad $(3,17-29 ; 10,6-18 ; 10,19-11,6 ; 20,11 ; 32,18)$.

En su intento por abarca la mayor cantidad de situaciones de la vida cotidiana, Sirá también aborda otros temas secundarios y hasta poco convencionales: la crianza de los hijos $(30,1-13 ; 42,9-14)$, el respeto a los padres $(3,1-16 ; 7,22-28)$, la salud $(37,27-15)$, la actitud ante la muerte $(38,16-23 ; 41,1-4)$, el gobierno $(9,17-10,5)$, la medicina (38,1-15), los buenos modales al comer (31,1-13), los sueños (34,1-8), las borracheras $(31,25-31)$, las pasiones $(6,2-4)$ y otros más.

\section{Las notas al final del pergamino}

Las ideas o consejos de cualquier persona, incluso las de un sabio no siempre tienen su génesis en la creatividad de quien reclama la autoría para sí o de quien se la asigna. Viene de alguna parte. Pero en el caso de Ben Sirá, como en nuestras vidas, las fuentes son plurales.

A pesar del mismo testimonio de Ben Sirá y de su nieto, que nos hacen ver que el primero es "el autor" de la sabiduría contenida en libro que lleva su nombre, es razonable suponer que las ideas allí descritas se deben a las aportaciones de los grandes maestros de Israel que le precedieron. No debemos olvidar al mismo pueblo hebreo, que bien pudo ser originador de muchos de los proverbios o principios que, a menudo, se parafrasean en esta obra. En cuanto al contenido, género y ordenamiento de las ideas, la dependencia de la Torá y de otras secciones de la Biblia Hebrea son claras, si bien no encontramos muchas citas directas del AT. De hecho, Jesús crea una atmósfera en la que a nivel conceptual y sintagmático hay obvias conexiones vivenciales con

18 Desde un punto de vista androcéntrico y reflejando valores de la clase alta, a la mujer se la presenta en Eclesiástico de forma positiva y negativa, siempre con relación al hombre (como hija, esposa, madre, adúltera y prostituta). Schüller, pp. 237-238. 
casi todo el AT, especialmente el libro de Proverbios ${ }^{19}$. Las únicas excepciones parecen ser Esdras, Daniel, Ester y Rut. El escritor ha enmarcado sus consejos dentro de la piedad del judaísmo del segundo templo, además del sistema de gobierno y los códigos de ley y sacrificios de ese entonces $(2,16 ; 9,15 ; 15,1 ; 17,11 ; 19,20 ; 21,11 ; 32,14-16 ; 34,8.39-11$; 51:19). Estudios especializados han detectado algunas similitudes con la literatura griega y la egipcia ${ }^{20}$.

A esta lista debemos adicionar los muchos viajes por el mundo y las innumerables lecciones que la vida le enseñó a Jesús. En sus propias palabras: "El que ha viajado mucho sabe muchas cosas, y el hombre de experiencia habla inteligentemente. El que no ha sido probado sabe pocas cosas, pero el que ha andado mucho adquiere gran habilidad" (24,11-12; Cf. 39,4). Razón tienen quien afirman que muchos de nosotros nos hemos formados en "la universidad de la vida".

\section{Del idioma hebreo a otras lenguas}

El libro de Ben Sirá fue escrito en hebreo. El problema es que el texto original desapareció y pudo sobrevivir gracias a traducciones a otros idiomas y copias de éstas, no siempre antiguas, uniformes o completas. Además de ello, las frecuentes omisiones, transposiciones y adiciones de capítulos y versículos han complicado la historia de la transmisión del texto de este libro. Esta situación ha dificultado los esfuerzos por reconstruir "el texto matriz" para estandarizar las traducciones a los idiomas modernos a fin de facilitar su interpretación.

El texto de Eclesiástico ha llegado a nuestras manos por medio de dos tradiciones o tipos de manuscritos. La primera por medio de una serie de traducciones al griego fuera de Palestina, siendo la primera de ellas la hecha por el nieto de Sirá. La segunda tradición textual nos ha llegado por medio de copias hebreas del manuscrito original hebreo, quizá iniciada por los discípulos del Sirácida en Jerusalén ${ }^{21}$, antes de que el original fuese traducido al griego.

Reconociendo que el griego realmente no capta los matices propios de la lengua hebrea, y después de invertir muchísimo tiempo y

19 Ver, por ejemplo, las notas al pie de algunas Biblias de estudio y sitios web que reproducen el libro de Ben Sirá. http://www.vicariadepastoral.org.mx/sagrada_escritura/biblia/antiguo_ testamento/46_eclesiastico_01.htm

20 Por ejemplo, hay similitudes con las ideas del poeta griego Teognis, y con algunas de las instrucciones demóticas egipcias encontradas en el papiro Insinger. Harrington, p. 79.

21 También existen dos traducciones tempranas al siríaco, una del hebreo y otras del griego. Otras traducciones fueron hechas a otros idiomas a partir del siríaco. Mezter, pp. 79-80. 
energía, el nieto del Sirácida afirma que él fue el autor de la primera traducción griega, la cual sirvió de matriz para otras copias griegas que circularon en varios lugares de la antigüedad y adquirieron mucha popularidad. Sin poder determinar si éstas son copias fieles de la primera traducción hecha por el nieto del Sirá, estas copias llegaron a ser parte de la versión griega del AT, popularmente conocida como la Septuaginta o la LXX. Los mejores manuscritos de la versión completa de esta sección de la Biblia son unciales del siglo IV d.C.: el Vaticano, el Sinaítico, el Alejandrino y varios minúsculos (normalmente designados como Griego I). Otra tradición de copias griegas (normalmente designadas como Griego II) es más tardía y está representada por el manuscrito 248 y otros minúsculos, la cual sirvió de base, junto con la traducción de la LXX, al latín (Griego I), para la mayoría de las traducciones modernas. El problema es que este tipo de copias añaden al texto conocido de Ben Sirá 150 versículos no contenidos en la LXX. En los manuscritos griegos también existe una doble numeración de los capítulos 30 al 36 o una alteración del orden: 33,13b-36,16a ha tomado el lugar de 30,25-33,13a. Además, la Vulgata Latina incluía sólo los capítulos 1-43 y 51, y para los capítulos 44-50 se utilizaron manuscritos latinos del siglo VI d.C.

Curiosamente, el libro de Sirá, mucho después de habernos llegado en griego, sobrevivió también por medio de manuscritos escritos en hebreo, pero incompletos y correspondientes al período medieval (siglos XI y XII). Dos tercios del texto hebreo aparecen en los manuscritos descubiertos a finales del siglo XIX en Egipto (Cairo Genizah), además de contener dos recensiones. En algunos fragmentos de los manuscritos de las cuevas del Qumrán, descubiertos en 1952, aparece el pasaje de 6,20-31, el cual concuerda con el del Cairo. La relación de todos estos documentos tardíos con la tradición griega (particularmente con relación a la LXX) es asunto debatido en algunos especializados. Otros manuscritos fueron descubiertos en Masada pero están incompletos; sólo aparecen los capítulos 39 al 43 pero con algunas lagunas ${ }^{22}$.

\section{Género distintivo entre tantas especies}

En cuanto a estilo de comunicación como estrategia pedagógica y persuasiva, el libro de Ben Sirá bien pudiera compararse a un mosaico de múltiples tonalidades afines, pero con un color resaltante. La

22 Metzger, pp. 79-80; Olvera Pérez, pp. 916-917; Rost, pp. 66-67; Boadt, p. 487; Harrington, pp. 79 y 89. 
temática, el propósito, el entorno y las circunstancias de vida de sus originadores y destinatarios así lo requieren.

Estrictamente hablando, y parecido a la conformación del libro de Proverbios, Eclesiástico es una colección de dichos y preceptos selectos que encarnando una serie de valores éticos, que reinterpretan la Ley de Moisés y otras secciones del AT, enseñan cómo vivir la vida de una manera práctica y consistente.

Alrededor de estos dichos y preceptos Sirá articula una gran variedad de unidades temáticas, que apelan a muchísimas situaciones de la vida real del pueblo hebreo y aun de otras culturas. Pero contrario a la tendencia del libro de Proverbios, en Eclesiástico encontramos mucho más que la simple cita de aforismos; por muy breve que estos sean, casi siempre hay una explicación que les sigue. El uso de ensayos es común. Aunque algunos pasajes son escritos en prosa, constantemente el autor recurre a los paralelismos característicos de la poesía hebrea. Muy popular es la técnica de utilizar las estrofas duales en las que la segunda dice la idea contraria a la primera, repite la misma idea de otra manera o resume lo dicho en la primera (bicola). Hay unos 1600 versículos redactados de esta manera ${ }^{23}$.

Dentro de este compendio de aforismos exhortativos, encontramos también otros géneros literarios que embellecen a Eclesiástico y contribuyen a lograr su objetivo formativo. Así pues, notamos la presencia de himnos de alabanza (1,1-10; 16,24-17,14; 24,1-29; 39,12-35; 42,15-43,33; 51,1-30) y oraciones reminiscentes de los salmos (22,25-23,6; 36,1-19; 50,25-26) y también algunas bienaventuranzas (14,1-2.20-21; 25,8-9; $26,1 ; 28,19 ; 31,8 ; 34,15 ; 50,28)$. Al cierre del libro, y siguiendo el orden de los libros del canon, el sabio Jesús comparte una serie de elegías que destacan la fe, el carácter y las hazañas de muchos de los héroes de la fe de Israel $(44,1-49,16)$, convirtiéndose en el primer escritor del género de sabiduría que incorpora la historia del pueblo hebreo con fines moralizantes. La historia, la sabiduría y la ética caminan de la mano.

Como parte de su estrategia comunicativa, el maestro Jesús se vale del uso de fórmulas prohibitivas $(4,20-5,9 ; 5,1-6 ; 7,1-20 ; 8,1-9,12$; $11,23-24 ; 15,11-12 ; 16,17)$, preguntas retóricas $(1,2-3.6-7 ; 7,22-24$; $10,19)$, analogías $(21,2-3 ; 24,13-17 ; 39,12-14 ; 50,1-10 ; 51,15)$, refranes o repeticiones $(2,17-18 ; 6,14-16 ; 7,22-24 ; 10,19 ; 19,13-17 ; 22,11-12$; $40,18-27 ; 41,14-42,14)$ y el uso de números para hablar de las virtudes y los vicios morales $(25,1-2.9 ; 26,5)$.

${ }^{23}$ Rost, p. 69. 


\section{La lógica armazón con fines formativos}

El compendio del Sirácida en su versión griega, aparte de sus distintivas características estilísticas y retóricas, está inserto en un andamiaje de 51 capítulos, el cual no parece seguir una estructura discernible y predecible. De hecho, en Eclesiástico existe la multiplicidad de coherencias temáticas, estilísticas y organizativas propias de la cultura hebrea.

Utilizando criterios no siempre coincidentes, los estudiosos proponen varios sistemas de ordenamiento general para ver el libro como un todo. Esta variedad es enriquecedora para quienes hayan tenido el placer de un acercamiento formal, que revela la sabiduría, aunque a otro nivel. A pesar de ello, Ben Sirá parece estar estructurado de acuerdo a tres bloques principales: (1) 1,1-23,27; (2) 24,1-42,14, y (3) 42,15-50,29).

Existen también algunos recursos organizativos más específicos. Por ejemplo, aparte de un interesante prólogo añadido a posteriori por el nieto de Jesús Ben Sirá, que explica la ocasión y el propósito del libro original del Sirácida, al igual que la necesidad y el objetivo de la traducción para un público más amplio ${ }^{24}$, se estima que el capítulo 1 es como una especie de introducción, cuyo temática central (1,1-10) haya eco en el resto del libro en lugares claves, por medio de una amplia gama de experiencias de vida a la que la sabiduría apela o ejemplifica. El capítulo 51 es un apéndice y notamos algunas oraciones interpoladas $(22,25-23,6 \text { y } 36,1-19)^{25}$. Puesto que la sabiduría no es estática, y cada momento histórico puede adicionar axiomas de fe y moralidad a la vida, es natural que otros textos se incorporen a un manuscrito en proceso de constante renovación. Con frecuencia, y para darle un toque un poco más íntimo y personalizado, el autor se dirige a sus pupilos en formación con el apelativo singular "hijo mío" $(3,12.17 ; 4,1 ; 6,18.23$. $32 ; 7,3 ; 10,28 ; 11,10 ; 14,11 ; 16,24 ; 18,15 ; 21,1 ; 31,22)$.

Puesto que el libro carece de una estructura de pensamiento lineal servida de una clara prosa, no parece que haya sido diseñado para ser leído de principio a fin. Invita a la pausa, a la memorización, a la reflexión y al diálogo. Por esta razón se utilizó para la educación de los iniciados en la escuela de Jerusalén y en la iglesia, siglos más tarde. Este formato es de utilidad para el discipulado de hoy, sobre todo

\footnotetext{
24 Lo cual, a pesar de ser común en el mundo helénico, es poco común en la Biblia (Cf. 2Mac 1,1932; Lc 1,1-4; Hch 1,1) Olvera Pérez, p. 919.

25 Rost, p. 68.
} 
en la educación popular. También es muy productivo el acercamiento temático, en base a textos claves, pero también tomando en cuenta una serie de versículos distribuidos por todo el libro.

\section{De lo secular a lo sagrado}

Aunque hay excepciones que validan la regla, "lo bueno" o "lo excelente" en el peregrinar humano tiende a ser preservado para la posteridad. El legado del Sirácida y la preservación de su pensamiento confirman lo dicho. Gracias a la traducción que su nieto hizo del libro de su abuelo, muchas comunidades palestinenses, la judería de cultura griega y la iglesia universal tuvieron la dicha de conocer a esta gran obra.

El posterior y popularizado uso de este libro, además de otros factores coyunturales, hicieron que éste llegara a formar parte de la LXX. Luego de un largo un largo y complejo proceso de depuración literaria, que incluyó a algunos libros y excluyó a otros, a la obra del "abuelo" se le confirió un sitial de honor en Las Escrituras griegas del pueblo de Israel. Pero su impacto transcendió lo que el mismo Jesús jamás intentó o hubiese imaginado: Ben Sirá llegó a formar parte de la Biblia de la tradición católico-romana y ortodoxa del cristianismo dentro del llamado "segundo canon" (o literatura deutero-canónica), por considerarlo "inspirado por Dios" y "autoritativo" -pero no sin las esperadas dificultades del caso $^{26}$. Los protestantes, reflejando otra postura, lo colocaron bajo el renglón de "libros apócrifos" por considerarlo "no inspirado".

A quien jamás se le hubiese ocurrido que esta colección de sabias lecciones de vida terminaría siendo parte de las Sagradas Escrituras, y que ayudaría a formar el carácter moral de judíos, cristianos y moralistas ${ }^{27}$. A ciencia cierta uno no puede saber, medir o anticipar la trayectoria e impacto que nuestros pensamientos pudieran tener en las vidas de otras personas. La historia siempre nos sorprende. Pero eso no quita que trabajemos con intencionalidad sobre nuestro legado y cómo nos ha de recordar la gente; es decir, nuestra reputación. En esto hay sabiduría.

26 San Jerónimo (340/50-420 d.C.), por ejemplo, conocía a Eclesiástico, aunque no estaba seguro de que se incluyera a Eclesiástico en el canon. El rabino Maimónides también supo de este libro (1135-1204 d.C.).

27 Es citado en el Talmud y la literatura rabínica del judaísmo muchas veces, a pesar de que no se le considera como inspirado. Sin embargo, el Concilio de Trento en el 1546 afirmó la canonicidad de Eclesiástico. Olvera Pérez, p. 917. 


\section{Tras más memorias para bordar el porvenir}

Célebre por sus prácticas admoniciones acerca de cómo actuar en ciertas situaciones de la vida, el libro de Jesús representa un gran aporte a la historia moral de la humanidad. Y aunque es imposible medir con su impacto o comprobar su efectividad con exactitud, sabemos algunas de sus recomendaciones hicieron honda mella en escritores como Santiago ${ }^{28}$, Jesús $^{29}$, otros pensadores cristianos $^{30}$ y la iglesia universal.

Las instrucciones del Sirácida son "copias al carbón" que apelan a muchas de las situaciones por las que pasamos. En relación al clima de violencia que se respira en muchos de nuestros países, no hay que "alegrase" por la muerte, pues a todos nos llegará un día $(8,7)$. Privar a los pobres de su sustento o a los trabajadores de su jornal es "matarlos" (34,21-22). Si nuestros gobernantes fueran sabios educarían al pueblo, ejercerían su autoridad con orden y escogerían a personas sabias también (10,1-2). La envidia, la rabia y las preocupaciones envejecen o acortan la vida $(30,24)$; la moderación es un buen antídoto contra las enfermedades $(31,22 ; 37,29-31)$ y la adicción al trabajo enferma $(11,10)$. Hay que escuchar, averiguar y pensar antes de hablar (11,7-9; Cf. 18,19-20; 20,1-8; 21,26). Pero en Sirá no falta el humor como recurso educativo: "El perezoso se parece a un montón de excrementos: el que los levanta se sacude las manos" $(22,2) ;$ "Un amigo burlón es como un caballo en celo: relincha bajo cualquier jinete" $(33,6)^{31}$. También es digno de encomio el esfuerzo de Eclesiástico por conectar su versión de la sabiduría con la historia de su pueblo narrada en las Escrituras ${ }^{32}$. Al compararlo con sus colegas de oficio, este fue un hito innovador en el pensamiento de aquella época. Por todas estas congruencias, generaciones más tarde,

28 Por ejemplo, 1,28; 2,1-5.12-14.17; 4,1-10; 5,11; 7,32-36; 11,2; 21,5; 23,9-11; 28,8-12; 29,10; 31,$3 ; 35,12-15 ; 38,1-15$.

29 6,24-25; 51,26-27; Cf. Mt 11,28-30.

30 4,31; Cf. Didaché 4,5; Carta de Bernabé 19,9. Harrington, p. 90.

31 Otros proverbios reflejan mucho nuestras experiencias. La manera como una persona se viste, mira o actúa es un reflejo de ella $(19,29-30)$. Lo barato sale caro $(20,12)$. Es falta de educación escuchar detrás de la puerta $(21,24)$. Hay que ahorrar cuando joven para que se tenga con qué vivir cuando viejo (25,3); quien revela secretos arruina la amistad (26,17.21). Una especie de ley del karma se da contra quien hace daño a los demás $(27,25-27)$. Es contraproducente solicitar consejo de alguien que no tiene experiencia o conocimiento $(37,10-11)$. La buena fama es perenne mientras que la felicidad tiene sus días contados $(41,13)$.

32 No hay que esperar hasta la lista de héroes, al final de su trabajo, pues las alusiones al AT están regadas por todas partes, especialmente con relación a las tradiciones del Pentateuco. 
sentimos ser parte de ese grupo de "aprendices" a quien el maestro cariñosamente llamaba "hijos".

Ahora bien, por muy válida que esta colección de máximas sea para el desarrollo ético de otras culturas, esto no debe llevarnos a pasar por alto su contextualidad, pues todas ellas fueron trabajadas en un momento, lugar y situaciones muy particulares, como fruto de una visión de mundo, distinta a la nuestra. No sería entonces cuerdo tratar de "trasplantar" algunos o todos los mensajes del Sirá al hoy sin el debido procesamiento y redimensionamiento. Nuestra irremediable trabazón con nuestros entornos y sus vertiginosos cambios, nos obligan a leer al Sirácida con otros prismas. Si Eclesiástico no tiene consejos para todas las situaciones de la vida del pueblo hebreo, mucho menos para las nuestras. Además, tanto la Biblia como nosotros no estamos exentos de las incongruencias morales. Lo que es "sabiduría" para algunos puede muy bien ser "ignorancia", traducida en "pecado", para otros. Procede el ser sensibles a las brechas, las disonancias y las ambigüedades que cada devenir conlleva.

Siguiendo estas tonadas, la sabiduría no debe privilegiar la experiencia de un solo pueblo (es decir, el hebreo) o sus portavoces, como si sus experiencias fueran una fórmula matemática repetible e indisputable. Reinterpretando el espíritu de 50,27: "la sabiduría de los pueblos ha sido plasmada en el libro de la vida y ha sido derramada como lluvia la sabiduría de sus corazones". Así que, si Dios la dio a todos "los hombres", sería lógico que la buscáramos en todas las vivencias humanas $(1,10)$, y no exclusivamente en las de "los eruditos" o el sexo masculino. No debemos permitir que la fuerza arrolladora del anonimato, confabulado con el síndrome de "las celebridades de las redes sociales", sepulte a "todos los sabios del barrio" al olvido, como si jamás hubiesen existido o no tuviesen nada que valiera la pena dejar como legado al conocimiento o la ética. Para llevar las palabras del sabio poeta a su lógica conclusión, las obras de justicia de "los hombres de bien" no deben ser olvidadas, pues "con su descendencia se perpetúa la rica herencia que procede de ellos" (44,9-10). ¿0 es que acaso son los letrados los únicos "expertos" de la vida? Y si la Sofía es como un cofre al que deben añadirse las joyas de las vivencias humanas que deben ser compartidas $(20,3)$; a ese tesoro debemos añadir también las joyas de nuestras visiones del mundo, enraizadas en los dichos populares de nuestras gentes y en la creatividad para solucionar nuestros problemas razonablemente. 
El enfoque de Ben Sirá en conductas y consejos dirigidos al individuo necesita ser complementado con un análisis de "las estructuras sociales" e "ideologías" que crean las condiciones para que esas conductas se gesten y afecten las relaciones humanas. Pero en nuestros esfuerzos por entender a nuestro mundo en términos más sistémicos y a larga escala, no perdamos de vista la simplicidad de la vida en situaciones tangibles. ¿Qué de malo hay en querer desarrollar una teología de "la amistad" o de "los buenos modales", por ejemplo, sin que se nos tilde de alienados, individualistas o vendidos al sistema imperante?

Dentro de un contexto de vida sensible a las estructuras y las coyunturas grupales y personales, se plantea también la cuestión de las complejidades y las aceleradas permutas de la digitalizada vida del siglo XXI, y dentro de esta nueva era sería superfluo el uso de "refranes" o "breves exhortaciones" para tomar muchas de nuestras decisiones; vivimos en medio de enmarañadas encrucijadas. Las generalidades que los aforismos suponen, necesitan especificidad para que aterricen en nuevos contextos de vida y por medio de mediaciones prácticas, muchas veces socio-políticas y económicas. Además, cabe preguntarse si es viable recordar 51 capítulos colmados de consejos (a veces contradictorios entre sí) para llevarlos a la práctica, cuando la situación se nos presenta en la cultura oral del Sirácida o en la nuestra. En el fragor de la confusión y la intensidad de las emociones, ¿será factible traer a la memoria la cita bíblica con el proverbio que mejor se aplica al caso? ¿O es que los consejos están diseñados para saber si acertamos o no después de nuestros actos?

Salvo algunas excepciones ${ }^{33}$, resaltar solamente "los logros" de ciertos personajes del AT, pasando por alto sus actos de violencia o ensalzándolos (44,1; 46,1-2.6.18), y a la vez marginando a las mujeres de "la galería de héroes", es pecar de un romanticismo tendencioso y vaciado de realismo histórico ${ }^{34}$, además de celebrar la injusticia. La caracterización machista de la mujer pisotea su dignidad (23,23-25; $25,13-26 ; 26,5-12 ; 42,14)$ y nos aleja del ideal de las relaciones de igualdad que deben reinar entre mujeres y hombres. Tejer a la sabiduría con los hilos del pasado y del presente, debería replantear el asunto de la idealización de los pobres y la satanización de los ricos que este libro remarca, pues las relaciones entre los dos grupos son bastantes

Por ejemplo, 47,11.19-20.23; 50,4.

Por ejemplo, la caracterización positiva de Josías $(49,1-3)$, la cual pasa por alto el genocidio de quienes profesaban una religión diferente. 
complejas. El odio profundo hacia el enemigo no es necesariamente algo "sabio" (50,25-26; Cf. 10,19; 12,4.5.7). El trato inhumano de los esclavos que se prescribe $(33,25-33 ; 42,1.5)$ y mucha de la posición que Sirá adopta sobre la disciplina de los hijos (30,1-13), más que sabiduría refleja crueldad y bajeza. ¿Cómo redibujar la imagen de ese "Dios justiciero" (de quien, paradójicamente, viene lo bueno y lo malo: $11,14)$ que, pese a sus muchos actos de generosidad y bondad, usa a la violencia como recurso pedagógico contra Israel y sus enemigos y, a cambio, recibe loores de musa y rima en los himnos y las oraciones del Sirá $(36,1-9)$ ? Y si la traducción griega de la versión original de Eclesiástico no tiene la misma fuerza que la del hebreo y hay mucho que se pierde en el proceso de conversión lingüística al hablar de la sabiduría, ¿no sería la dependencia del griego o cualquier idioma posterior (el español, por ejemplo) un serio impedimento para entender realmente "la sabiduría" de la que el Sirá habló, pero en hebreo?

Seguir en pos de "la Madre Sabiduría", mientras le damos un toque de realismo a su idealización $(50,13-3)$, para divisar su fulgor y algún día conocerla en su mágico esplendor, es transitar por un camino angosto y tortuoso que además de llenar el alma de satisfacción, dura toda la vida. Se nutre del diario maná de la esperanza y de las inagotables aguas de las memorias preñadas y paridas en las danzas con el entretanto. En palabras del Ben Sirá, no es más que una manera de "luchar por conseguirla" (51,13-14.19), de "buscar sus huellas" $(51,15)$ y dirigir "nuestras almas hacia ella" $(51,20)$, pues, en el fondo, sabemos que la verdadera sapiencia "está tan cerca que se la puede alcanzar" $(51,26)$. Es por ello que, siguiendo la luz divina grabada en las huellas de la sapiencia de nuevas auroras $(50,29)$ y colocando los ojos en nuevos horizontes, seguimos haciendo nuestra la musa de las vivencias hechas recuerdos, para ceder el paso a más recuerdos: "Sigue sus huellas y búscala: la sabiduría se te dará a conocer, y una vez que la poseas, no la dejes, porque al fin encontrarás en ella el descanso y ella se convertirá en tu alegría" (6,27-28). 